(c) American Dairy Science Association, 2003.

\title{
Birth Weight as a Predictor of Calving Ease and Perinatal Mortality in Holstein Cattle ${ }^{1}$
}

\author{
J. M. Johanson and P. J. Berger \\ Department of Animal Science, \\ lowa State University, Ames 50011-3150
}

\begin{abstract}
The objective of this research was to determine the effect of birth weight on perinatal mortality (PM) (alive or dead at $48 \mathrm{~h}$ of age) and dystocia (unassisted or assisted). Data were 4528 records of births between 1968 and 1999 from the Iowa State University research dairy farm in Ankeny. The incidence of PM was 7.1\%; dystocia was $23.7 \%$. A logistic regression model was used to predict both PM and dystocia. The PM model included effects of year of birth, season (summer or winter), dystocia, parity (first or later), birth weight $(\mathrm{kg})$, ratio of calf's birth weight to dam's weight (\%), and gestation length (d). Odds of PM increased by $2.1 \% / y$. Calves born in the winter have a $36 \%$ higher risk of PM than calves born in the summer. Difficult births tend to result in PM 2.7 times more often than unassisted births. Firstparity cows have a 2.4 times higher risk of PM than cows in later parities. Probabilities of PM for birth weights of $29,35,40,46$, and $52 \mathrm{~kg}$ were $2.1,2.5,3.4,5.1$, and $9.6 \%$, respectively, when other factors were set at their average value. Similarly, ratios of calf to cow weight of 4.5, 5.7, $6.9,8.1$, and $9.3 \%$ yield probabilities of PM at 8.2, 4.2, 3.1, 3.5 , and $5.7 \%$, respectively. Finally, gestation lengths of $268,273,279,284$, and $290 \mathrm{~d}$ yield probabilities of PM of $5.5,3.9,3.1,3.1$, and $3.6 \%$, respectively. The dystocia model included effects of year of birth, season, sex of calf, PM, parity, birth weight, and pelvic area (externally measured). Odds for dystocia decreased by $4.7 \% / \mathrm{yr}$. Calves born in the winter have a $15 \%$ higher risk of dystocia than calves born in the summer. Odds of male calves needing assistance were $25 \%$ greater than female calves. If a calf died in the first $48 \mathrm{~h}$, then it is 2.7 times more likely that the calf needed assistance. First-parity cows have a 4.7 times higher risk of dystocia than cows in later parities. Odds of dystocia increase by $13 \% / \mathrm{kg}$ increase in birth weight. An $11 \%$ decrease in odds for
\end{abstract}

\footnotetext{
Received January 29, 2003.

Accepted June 20, 2003.

Corresponding author: P. J. Berger; e-mail: pjberger@iastate.edu.

${ }^{1}$ Journal Paper of the Iowa Agriculture and Home Economics Experiment Stations, Ames; Project Number 3538, and supported by Hatch Act and State of Iowa Funds.
}

dystocia is associated with a one square decimeter $\left(\mathrm{dm}^{2}\right)$ increase in pelvic area.

(Key words: birth weight, dystocia, Holstein, perinatal mortality)

Abbreviation key: AIC = Akaike's Information Criterion, $\mathbf{C E}=$ calving ease, $\mathbf{M R R 2}=$ max-rescaled $R^{2}$, $\mathbf{O R}$ = odds ratio, $\mathbf{P A}=$ pelvic area, $\mathbf{P M}=$ perinatal mortality .

\section{INTRODUCTION}

\section{Dystocia and Perinatal Mortality}

Perinatal mortality (PM), defined as a death before $48 \mathrm{~h}$ of age, and dystocia are unfavorable traits for dairy producers. A difficult birth can cause trauma both for the cow and the calf. The cow may experience reduced milk production or uterine infection, resulting in additional veterinary costs and decreased fertility, which may lead to premature culling (Dematawewa and Berger, 1997). On rare occasions, the cow may need to be slaughtered or euthanized. A difficult parturition can substantially increase the calf's risk of death. It is quite costly to replace the dead calf, especially a dead heifer calf. Dematawewa and Berger (1997) estimated the value of a male calf to be $\$ 70$ and a female calf to be $\$ 150$. Dystocia may also contribute to additional management costs for continuous surveillance of parturient cows. Dematawewa and Berger (1997) estimated costs associated with dystocia to be $\$ 0.00,50.45,96.48,159.82$, and 397.61 for no assistance, slight assistance, needed assistance, considerable force needed, and extreme difficulty, respectively. Also, Dematawewa and Berger (1997) estimated total average cost of dystocia for primiparous cows was $\$ 28.01$ compared with $\$ 11.10$ for multiparous cows. In a different analysis, Dekkers (1994) calculated dystocia costs to be $\$ 43.11$ and $\$ 20.25$ for first and later parities, respectively.

Currently in the United States, there is a genetic evaluation of sires and maternal grandsires for dystocia, but there is no formal evaluation for PM. Calving ease is a trait considered to be correlated with PM. In spite of the availability of calving ease evaluations, Meyer et al. (2001a) observed an increasing phenotypic trend in PM from 1985 to 1996. In first-parity cows, the incidence of 
Table 1. All effects considered for inclusion in this analysis. Note that not all effects were found to be valuable predictors of perinatal mortality or dystocia.

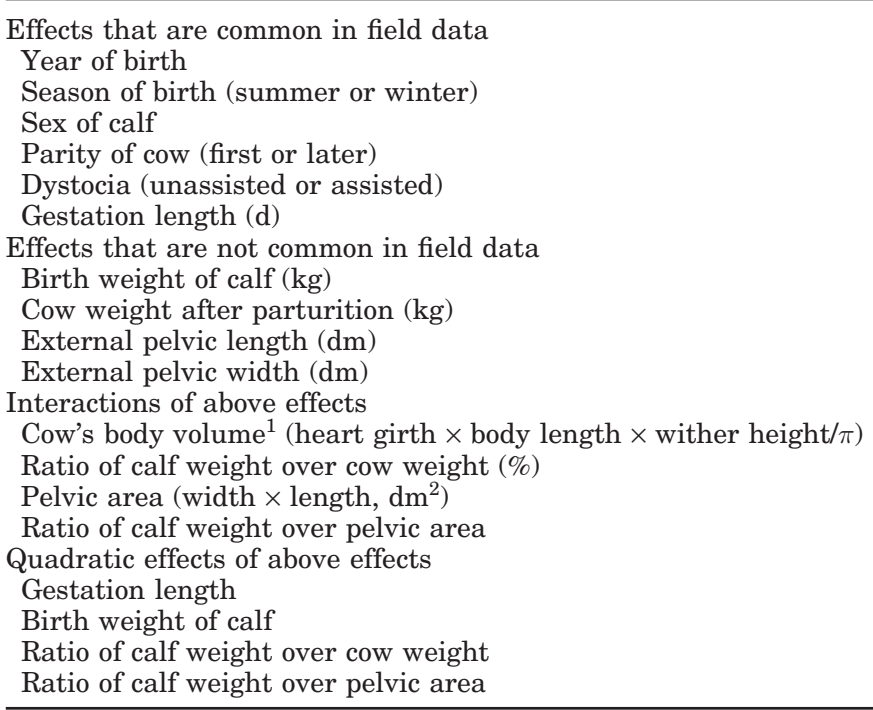

${ }^{1} \mathrm{P}$. Hoffman, personal communication.

stillbirths increased from 9.5 to $13.2 \%$, and in later parity cows it increased from 5.0 to $6.6 \%$. Meyer et al. (2001b) also found an increasing genotypic trend among US sires. Either 1) producers are ignoring the evaluations and are more interested in selecting for milk yield, 2) the evaluations are inadequate to produce favorable genetic changes, or 3) a reduction in difficult births is not resulting in a reduction in PM. Whatever the reason, PM is becoming a problem and should not be neglected any longer.

\section{Associated Traits}

Meijering (1984) extensively reviewed of traits that are associated with dystocia and stillbirth. Meyer et al. (2000, 2001a, 2001b) studied traits that were collected from field data. In addition to traits found in field data, this study investigates several factors that may be associated with PM and dystocia that are not commonly measured in field data. Table 1 lists all effects considered in the analysis; however, not all the traits were found to be significant. Therefore, only significant effects were included in the final models. McDermott et al. (1992) found that birth weight is the most important factor in predicting dystocia. As for PM, Berger et al. (1992) noted that calves that are lighter and heavier than average tend to have more PM. Unfortunately, birth weight is not commonly measured in field data for Holsteins. Meijering (1984) concluded that birth weight's impact on incidence of dystocia is nonlinear, but it sometimes is mistakenly modeled as a linear effect. One of the primary interests of this study is to determine the impact of birth weight.

The objectives of this study are: 1 ) to determine the best model to predict PM and dystocia given the information available in field data and additional variables with more intensive data recording on research farms and 2) to determine the value of birth weight in the predicted model.

\section{MATERIALS AND METHODS}

\section{Data}

The data were collected at the Iowa State University dairy farm in Ankeny. Values that were more than three standard deviations away from the mean were omitted (birth weight, 12 discarded; ratio of calf weight over cow weight, 17; gestation length, 46). If any trait included in the analysis was missing a value, the SAS analysis omitted that observation. We did not include twins or malpresented calves in this analysis, because we were primarily interested in what causes correctly presented single-born calves to die or be difficult to deliver. However, twins are noted to have higher PM and dystocia rates than singletons (Johanson et al., 2001). The five dystocia categories used in this herd were established when the herd was founded in 1968. Unfortunately, our categories do not correspond directly with the categories used in the more recently applied US national data recording scheme for dystocia. The best way to align the two recording systems was to condense the five dystocia categories down to only two, assisted and unassisted. The assisted category includes all births that were assisted by manual pull, chain pull, jack, or caesarean. Season was classified as summer and winter. Summer included April, May, June, July, August, and September; while winter included October, November, December, January, February, and March. Parity was grouped as primiparous cows in one group and multiparous cows in the other group, with parities ranging from 2 up to 10. Heifers must have reached 14 mo of age and must have weighed $340 \mathrm{~kg}$ before they were bred.

After editing, the incidence of perinatal mortality was $7.1 \%$. The incidence of dystocia was $23.7 \%$. The dataset used to model perinatal mortality contained 4528 calvings, and the dataset used to model dystocia contained 4111 calvings. Perinatal mortality is defined as a death of the calf within the first $48 \mathrm{~h}$ after parturition. The protocol for providing assistance is to give the cow $2 \mathrm{~h}$ without assistance after the appearance of the calf's feet. If the cow does not make progress after the 2 -h waiting period, assistance is then provided. The primary difference in the total number of observations was because pelvic area is found to be significant in the model for dystocia, but not significant in the model for PM. The 
Table 2. Means and standard deviations of continuous variables.

\begin{tabular}{|c|c|c|c|c|}
\hline Variable & Parity $^{1}$ & $\mathrm{~N}^{2}$ & Mean & SD \\
\hline \multirow[t]{2}{*}{ Birth weight (kg) } & $\mathrm{P}$ & 1753 & 38.2 & 5.1 \\
\hline & M & 2775 & 41.7 & 5.6 \\
\hline \multirow[t]{2}{*}{ Gestation length (d) } & $\mathrm{P}$ & 1753 & 277.9 & 5.4 \\
\hline & M & 2775 & 279.2 & 5.6 \\
\hline \multirow[t]{2}{*}{ Cow weight (kg) } & $\mathrm{P}$ & 1753 & 512.1 & 55.0 \\
\hline & M & 2775 & 644.2 & 71.0 \\
\hline \multirow{2}{*}{$\operatorname{Ratio}^{3}(\%)$} & $\mathrm{P}$ & 1753 & 7.5 & 1.2 \\
\hline & M & 2775 & 6.5 & 1.0 \\
\hline \multirow[t]{2}{*}{ Pelvic area ${ }^{4}\left(\mathrm{dm}^{2}\right)$} & $\mathrm{P}$ & 1850 & 27.0 & 2.2 \\
\hline & M & 3023 & 31.2 & 2.5 \\
\hline
\end{tabular}

${ }^{1} \mathrm{P}=$ primiparous and $\mathrm{M}=$ multiparous.

${ }^{2} \mathrm{~N}=$ number of observations.

${ }^{3}$ Ratio is the calf birth weight divided by the cow's weight expressed as a percentage.

${ }^{4}$ Pelvic area is externally measured in square decimeters $\left(\mathrm{dm}^{2}\right)$.

analysis procedure automatically drops records with missing values when those values are needed for the analysis. There were 402 records missing pelvic area measurements. These records were included in the first analysis of PM (when pelvic area was not included in the model), but omitted from the second analysis of dystocia (when pelvic area was included in the model).

Table 1 has all factors that were considered to be potentially valuable predictors of PM and dystocia. Note that not all of these factors were found to have significant effects on dystocia or PM. Table 2 has summary statistics for the continuous traits used in the final model. Table 3 has the incidences of dystocia and PM by parity.

\section{Logistic Regression Analysis}

Because both PM (alive or dead) and dystocia (assisted or unassisted) are binary traits, a traditional regression model for a continuous trait cannot be used. We chose to use logistic regression to model both PM and dystocia. Logistic regression handles binary variables well and gives results that are easy to interpret. The logistic regression analysis was done using PROC LOGISTIC in
SAS (1999). Within the logistic regression procedure, SAS has score and stepwise procedures to assist in determining the best model. An introductory text about logistic regression is Kleinbaum (1994), and a more statistically rigorous text is Hosmer and Lemeshow (2000).

Odds ratio. Odds ratios (OR) are another useful way to interpret results from a logistic regression analysis (Kleinbaum, 1994; Hosmer and Lemeshow, 2000). An OR compares two opposing probabilities to determine which is more problematic. For example, we may want to compare dystocia in male calves versus dystocia in female calves. If the OR is exactly equal to 1 , then there is no difference between the sexes for the odds of dystocia. In that case, sex of the calf would not be a good predictor of dystocia. If the OR is 1.5 , we interpret this value as meaning male calves have a $50 \%$ greater chance of dystocia than female calves given that all other variables are the same. An OR of 2 is double the risk.

The OR above was for a discrete variable such as sex of calf. An OR can also be calculated for a continuous variable. This type of OR can be interpreted as a linear trend over the range of the variable. For example, an OR of 1.05 for year is interpreted as a $5 \%$ increase in

Table 3. Counts and proportions of perinatal mortality $(\mathrm{PM})$ and dystocia within primiparous and multiparous cows.

\begin{tabular}{|c|c|c|c|c|}
\hline Parity & PM & Unassisted & Assisted & Total \\
\hline \multirow[t]{2}{*}{ Primiparous } & alive & $\begin{array}{l}972 \\
(21.5 \%)^{1}\end{array}$ & $\begin{array}{l}586 \\
(12.9 \%)\end{array}$ & $\begin{array}{l}1558 \\
(34.4 \%)\end{array}$ \\
\hline & dead & $\begin{array}{l}72 \\
(1.6 \%)\end{array}$ & $\begin{array}{l}123 \\
\quad(2.7 \%)\end{array}$ & $\begin{array}{l}195 \\
(4.3 \%)\end{array}$ \\
\hline \multirow[t]{2}{*}{ Multiparous } & alive & $\begin{array}{l}2323 \\
(51.3 \%)\end{array}$ & $\begin{array}{l}325 \\
\quad(7.2 \%)\end{array}$ & $\begin{array}{l}2648 \\
\quad(58.5 \%)\end{array}$ \\
\hline & dead & $\begin{array}{l}86 \\
(1.9 \%)\end{array}$ & $\begin{array}{l}41 \\
(0.9 \%)\end{array}$ & $\begin{array}{r}127 \\
\quad(2.8 \%)\end{array}$ \\
\hline Total & & $\begin{array}{l}3453 \\
\quad(76.3 \%)\end{array}$ & $\begin{array}{l}1076 \\
(23.8 \%)\end{array}$ & $\begin{array}{l}4528 \\
(100.0 \%)\end{array}$ \\
\hline
\end{tabular}

${ }^{1}$ Percentage of total. 


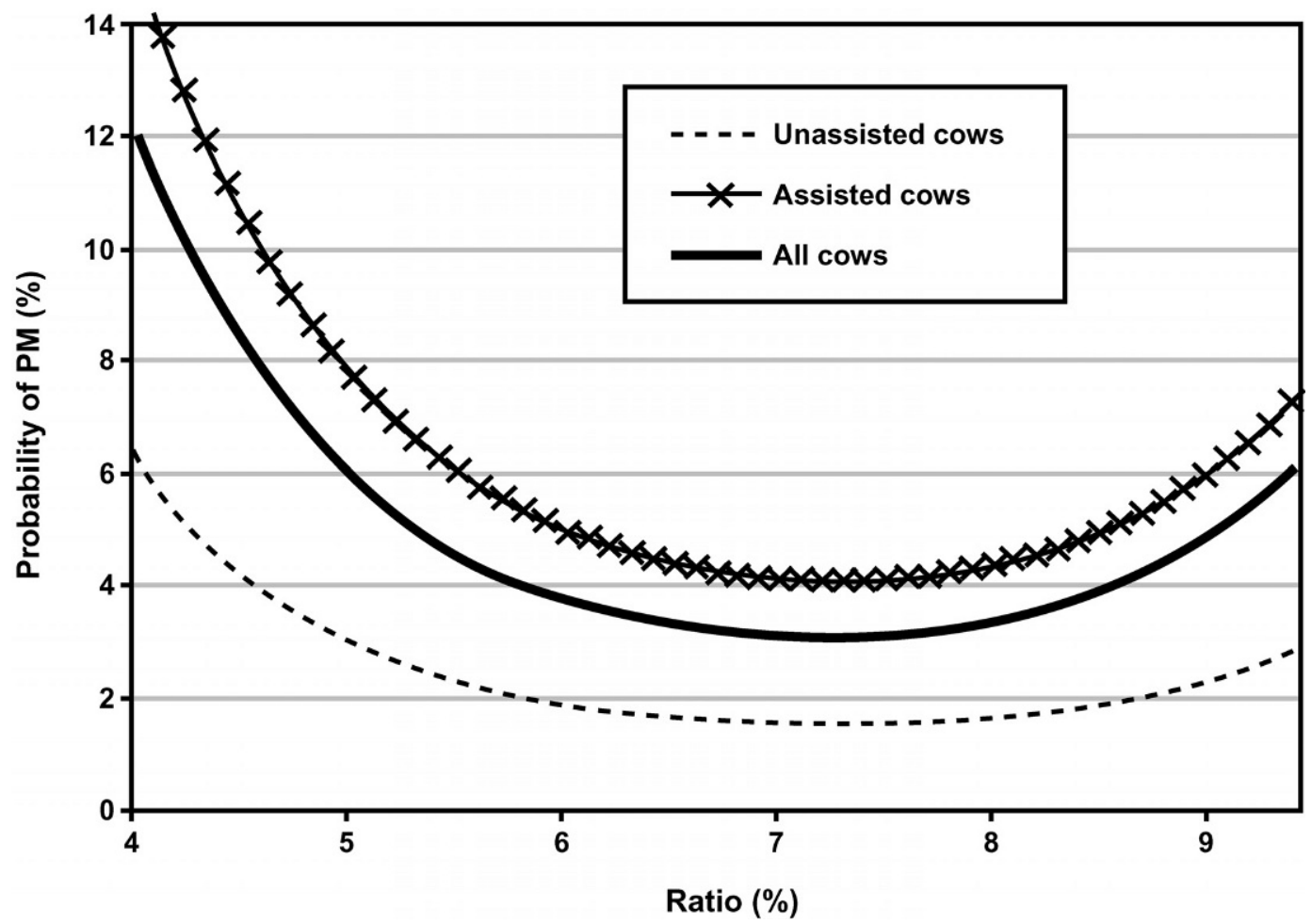

Figure 1. Graph of linear and quadratic effects of ratio on perinatal mortality (PM). Ratio of birth weight to cow weight has a mean value of $6.9 \%$ with a standard deviation of $1.2 \%$. The value of ratio with the minimum risk of PM is $7.2 \%$.

the OR for dystocia for the next year while the other variables are held constant. Suppose all calves born in 1988 have a $10 \%$ chance of needing assistance, then all calves born in 1989 have a $10.5 \%(10 \% \times 1.05)$ chance of needing assistance.

In our analysis, some of our variables are included as quadratic effects. In this scenario, the OR is not constant over the full range of values for the continuous variable, and, therefore, cannot be calculated directly. For variables of this sort, we plotted the probability curves for dystocia and PM (Figures 1, 2, and 3). This gives us a good representation of how the impact of the variable changes throughout its range of values.

Akaike's information criterion. The Akaike's Information Criterion (AIC) is a criterion to evaluate which model fits best (Akaike, 1969; Agresti, 2002). The smaller the AIC the better the model. The AIC includes a penalty for over-parameterization, so we should have a good balance between fit and number of parameter estimates given as

$$
\mathrm{AIC}=-2 \times \log \mathrm{L}-2 \times(k+s),
$$

where $k$ represents the number of response levels minus one and $s$ is the number of predictive effects (SAS, 1999).
Max-rescaled $\boldsymbol{R}^{2}$. The coefficient of determination, denoted as $R^{2}$, is a familiar term used in traditional linear regression. It describes the amount of variation that is accounted for by the regression model. Because logistic regression is a nonlinear regression, we cannot calculate an $\mathrm{R}^{2}$ value. However, Nagelkerke (1991) describes a generalization of $R^{2}$ to logistic regression called the Max-Rescaled $R^{2}$ (MRR2) that has the same interpretation as the traditional $R^{2}$ value.

\section{RESULTS AND DISCUSSION}

An earlier study on this same herd included observations from 1968 until 1986, dystocia was reported to be $52,20,17$, and $14 \%$ for first, second, third and fourth, or greater parities (Sieber et al., 1989). Our data include these observations as well as the addition of observations from the years of 1987 through 1999. In this analysis, first-parity cows had an incidence of dystocia at $40.4 \%$, while later parity cows have an incidence of $13.2 \%$. Also, PM has an incidence of 11.1 and $4.6 \%$ for first and later parities, respectively. The reduction of dystocia in the first parity from the Sieber et al. (1989) study to the present study may be due to a change in management strategies in recent years. Managers have changed at 


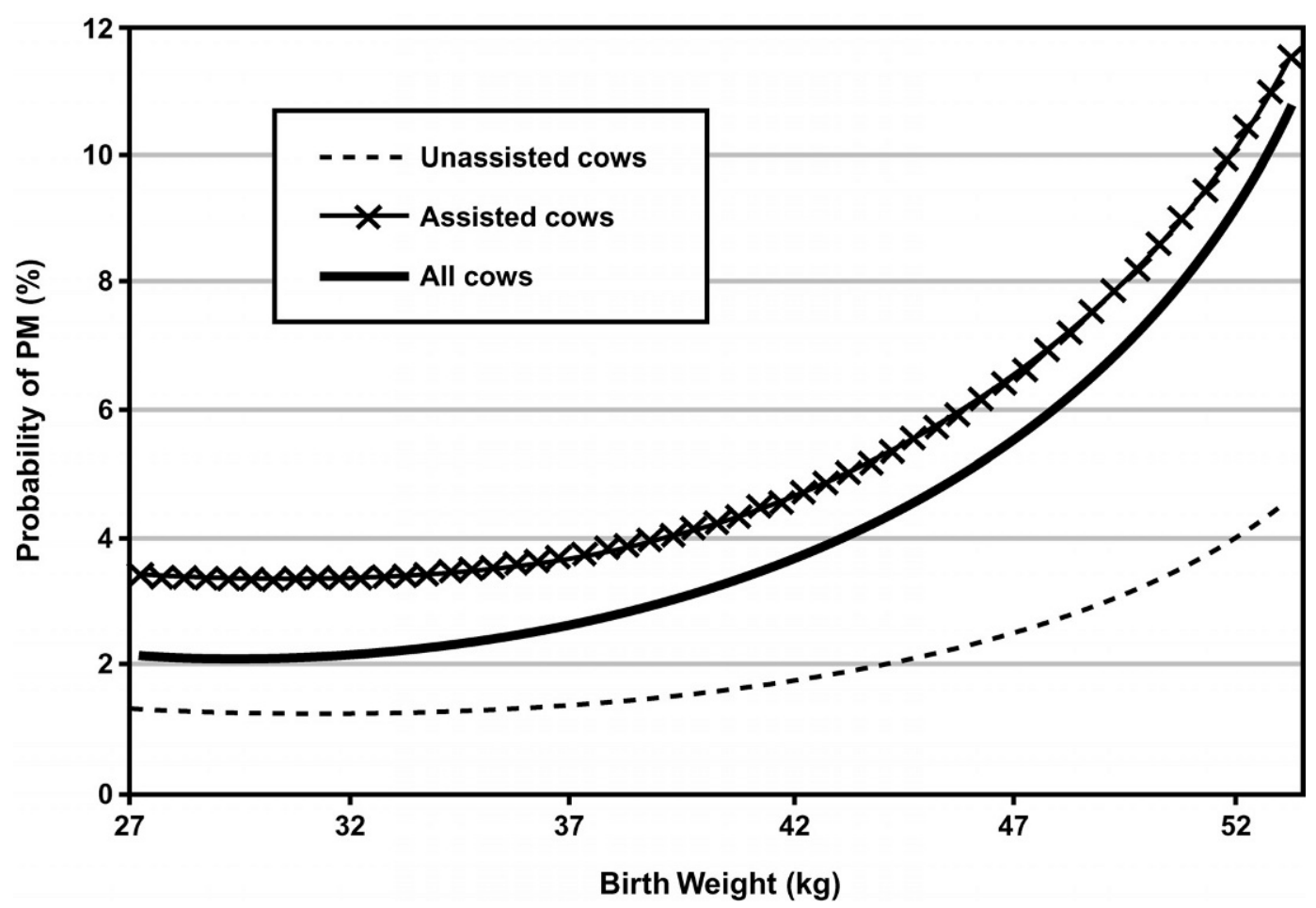

Figure 2. Graph of linear and quadratic effects of birth weight on perinatal mortality (PM). Birth weight has a mean value of $40.3 \mathrm{~kg}$ with a standard deviation of $5.7 \mathrm{~kg}$. Birth weights above $42 \mathrm{~kg}$ are at high risk of PM.

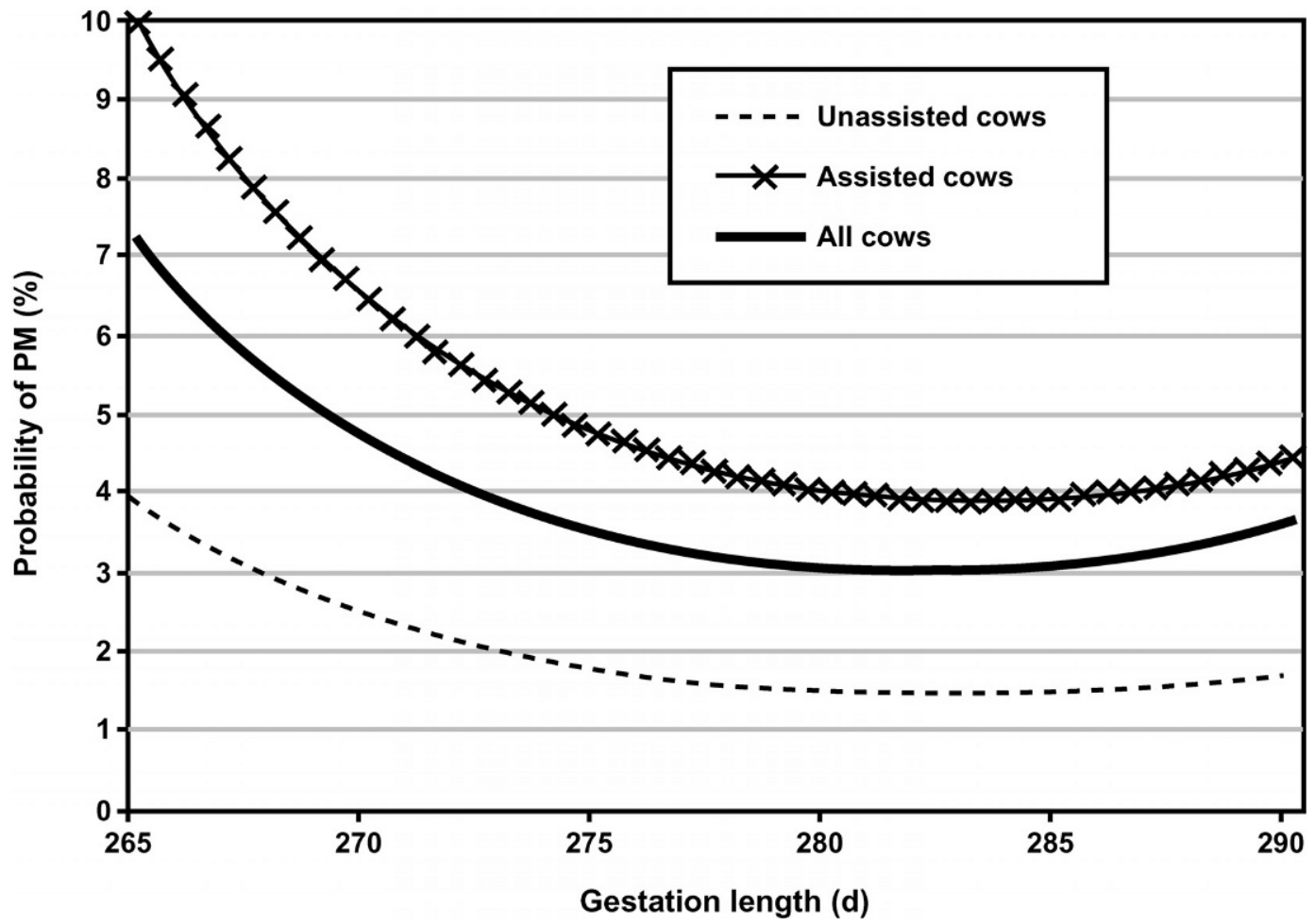

Figure 3. Graph of linear and quadratic effects of gestation length on perinatal mortality (PM). Gestation length has a mean value of $278.7 \mathrm{~d}$ with a standard deviation of $5.6 \mathrm{~d}$. The value of gestation length with the minimum risk of PM is $282 \mathrm{~d}$. 
Table 4. A comparison of five different models for PM. The $P$-values demonstrate the level of significance for each effect. Model 2 is the best model because it has the largest max-rescaled $R^{2}$ (MRR2) value and the smallest Akaike Information Criterion (AIC).

\begin{tabular}{lccccr}
\hline Effects of PM & Model $1^{1}$ & Model $2^{2}$ & Model $3^{3}$ & Model $4^{4}$ & Model $^{5}$ \\
\hline Year & $0.0065^{6}$ & 0.0065 & 0.0059 & 0.0007 & 0.0007 \\
Season & 0.0138 & 0.0138 & 0.0089 & 0.0111 & 0.0100 \\
Sex & 0.9167 & - & - & - & 0.1554 \\
Dystocia & $<0.0001$ & $<0.0001$ & $<0.0001$ & $<0.0001$ & $<0.0001$ \\
Parity & $<0.0001$ & $<0.0001$ & $<0.0001$ & $<0.0001$ & $<0.0001$ \\
Ratio & $<0.0001$ & $<0.0001$ & - & - & - \\
Ratio2 & $<0.0001$ & $<0.0001$ & - & - & - \\
Birth Weight & 0.0675 & 0.0672 & $<0.0001$ & - & - \\
Birth Weight2 & 0.0081 & 0.0080 & $<0.0001$ & - & 0.3680 \\
Gestation Length & $<0.0001$ & $<0.0001$ & $<0.0001$ & $<0.0001$ & $<0.0001$ \\
Gestation Length2 & $<0.0001$ & $<0.0001$ & $<0.0001$ & $<0.0001$ & 2135 \\
AIC & 2052 & 2050 & 2079 & 2135 & 0.1088 \\
MRR2 & 0.1572 & 0.1572 & 0.1402 & & \\
\hline
\end{tabular}

${ }^{1}$ Model 1 includes all effects.

${ }^{2}$ Model 2 drops the sex effect. Note that Model 2 is the best model with the lowest AIC and the highest MRR2.

${ }^{3}$ Model 3 also drops the ratio effect, if we do not have the cow's weight.

${ }^{4}$ Model 4 also drops both the ratio and the birth weight effect, if we do not have the calf's birth weight.

${ }^{5}$ Model 5 adds the sex effect back into the model as an ineffective attempt to regain the loss in predictive ability that the birth weight effect provided.

${ }^{6} \mathrm{P}$-value to test significance of the effect.

${ }^{7}$ Ratio is the calf birth weight divided by the cow's weight expressed as a percentage.

the farm between 1968 and 1999; however, the same protocol described earlier for managing cows and recording observations during the birth of every calf was maintained throughout the duration of this selection experiment. There was no selection of heifers based on their evaluation for calving ease. Howard Tyler (personal communication) found Holstein cattle need a lot of time to dilate for parturition. In recent years, different herd managers may have given individual cows more time to prepare for parturition before providing assistance.

\section{Perinatal Mortality Model Analysis}

Logistic regression model. Using score and stepwise procedures in SAS, the most parsimonious model was found to include the effects of year, season, dystocia, parity, linear and quadratic effects of ratio of calf to cow weights, linear and quadratic effects for birth weight of calf, and linear and quadratic effects of gestation length. Table 4 shows a few of the models investigated for predicting PM. Model 1 includes the sex of calf effect, which was expected to be an important factor in the model, but its importance is diminished when birth weight is included in the model (Meijering, 1984; McDermott et al., 1992). Sex of calf is then no longer a significant effect. model 2, which drops sex of calf from the model, results in the best model with the highest MRR2 value (15.7\%) and the lowest AIC value. Model 3 represents what would happen if we have birth weights but not the BW of the cows, which might be a possible scenario in the field. In such a scenario, we could not calculate the ratio effect. Model 3 has a relatively small loss of fit. This indicates that the ratio effect is not as valuable as the birth weight effect. Model 4 represents the absence of both birth weight and cow weight, which would be the case if we did not have birth weight records. This model has a large loss of fit. Without birth weight and cow weight in the model (See model 4 in Table 4), we lose approximately $1 / 3$ of our predictive ability, dropping the MRR2 down from 15.7 to $10.9 \%$. Dystocia differences between sexes may depend primarily on birth weight, because male calves are larger than female calves at birth (Meijering, 1984; McDermott et al., 1992). Because the birth weight effect appears to account for the sex difference, model 5 puts the sex effect back into the model to see if the sex effect can account for the missing birth weight effect. There is only a slight increase in the value of MRR2. Therefore, the birth weight effect explains more than just the sex effect. Clearly, birth weight is a better predictor of PM than the sex of the calf. The best logistic regression model (See model 2 in Table 4) is given in equation [1] as:

$$
\begin{gathered}
\log \left(\Pi_{\mathrm{PM}} /\left[1-\Pi_{\mathrm{PM}}\right]\right)=\beta_{0}+\beta_{1} \text { Year }+\beta_{2} \text { Season } \\
+\beta_{3} \text { Dystocia }+\beta_{4} \text { Parity }+\beta_{5} \text { Ratio } \\
+\beta_{6} \text { Ratio }^{2}+\beta_{7} \text { BW }+\beta_{8} \mathrm{BW}^{2}+\beta_{9} \mathrm{GL} \\
+\beta_{10} \mathrm{GL}^{2}
\end{gathered}
$$

where $\Pi_{\mathrm{PM}}$ is the probability of perinatal mortality, BW is birth weight, and GL is gestation length. Table 5 has 
Table 5. Parameter estimates for best perinatal mortality model (model 2, Table 4).

\begin{tabular}{lc}
\hline Parameter & Estimate \\
\hline Intercept & 206.7 \\
Year & 0.0207 \\
Season (winter) & 0.3075 \\
Dystocia (assisted) & 0.9946 \\
Parity (first) & 0.8882 \\
Ratio $^{1}$ (\%) & -1.9296 \\
Ratio $^{2}$ & 0.1329 \\
Birth weight (kg) $_{\text {Birth weight }}^{2}$ & -0.1528 \\
Gestation length (d) $^{2}$ & 0.00254 \\
Gestation length $^{2}$ & -1.7162 \\
\hline
\end{tabular}

${ }^{1}$ Ratio is the calf birth weight divided by the cow's weight after parturition expressed as a percentage.

significant parameters along with their estimates from the best model (model 2; Table 4). The ratio of calf weight to cow weight is clearly correlated with the calf's birth weight alone; however, it appears that ratio and birth weight explain different sources of variation. It is a wellknown fact that the sex of the calf has an effect on PM (Meijering, 1984; McDermott et al., 1992), but with the inclusion of birth weight and ratio effects, sex is no longer significant. Apparently, effect due to sex of calf is accounted for by including ratio and birth weight effects.

Odds ratios. Table 6 has estimates for the odds ratios for significant factors in the PM analysis. Although the effect of year is significant, there is a rather small increasing trend in the odds ratio for PM. The estimate of the odds ratio for year, 1.02, tells us that there is a $2.1 \%$ increase in the odds ratio for PM per year. For example, if the incidence of $\mathrm{PM}$ is $7.1 \%$ in a given year, then it will increase to $7.24 \%(0.071 \times 1.02)$ the next year. Season has a noticeable effect on PM. Calves born in the winter are $36 \%$ more likely to die in the first $48 \mathrm{~h}$ than calves born in the summer. The effect of dystocia gives the largest OR. The OR for dystocia can be interpreted to mean if a calf needs assistance, it has a 2.7 times greater chance of dying than a calf that is unassisted, given that all other factors are held constant. The effect of parity has a similar magnitude of effect as dystocia. Primiparous cows tend to have 2.4 times more PM in their calves than their multiparous counterparts.

Graphs of quadratic effects. It was mentioned previously that OR for quadratic effects cannot be calcu- lated. The best way to understand the impact of these factors is through graphs that show the changes over the range in value of the factors.

Ratio. Figure 1 shows the effect of the ratio of calf to cow weights. The ratio is calculated by dividing the calf's birth weight by the cow's weight measured 2 or $3 \mathrm{~d}$ after parturition. The graph shows ratios ranging over approximately two standard deviations from 4.5 up to $9.3 \%$ with a mean of $6.9 \%$ and a standard deviation of $1.2 \%$. In spite of having smaller calves $(38.2 \mathrm{vs} .41 .7 \mathrm{~kg}$, respectively), primiparous cows have a larger average ratio $(7.5 \%)$ compared with multiparous cows (6.5\%) (from Table 2). Jersey cattle tend to be excellent for calving ease with a ratio tightly distributed around 6\% (Howard Tyler, personal communication). It appears that Holsteins' best survival rate occurs when the ratio is close to $7.2 \%$. As the ratio gets small, the chance of PM for assisted calves becomes very large. This may be slightly exaggerated due to extrapolation of the model when there are very few observations. Most of the small ratios will be due to very small birth weights, and very few small calves need assistance. That being said, the effect of ratio on dystocia is strong. For all cows, ratios of calf to cow weight of $4.5,5.7,6.9,8.1$, and $9.3 \%$ yield probabilities of mortality at $8.2,4.2,3.1,3.5$, and $5.7 \%$, respectively. The intermediate optimum for ratio is $7.2 \%$. Therefore, an average calf with a birth weight of 40.3 $\mathrm{kg}(88.7 \mathrm{lbs})$ should be born to a cow weighing $559.7 \mathrm{~kg}$ (1231.4 lbs) to minimize the calf's chance of death (40.3 $\mathrm{kg} / 559.7 \mathrm{~kg}=7.2 \%)$.

Birth weight. Figure 2 shows the impact of birth weight on probability of PM. The graph shows birth weights ranging over approximately two standard deviations from 29 to $52 \mathrm{~kg}$ with a mean of $40.3 \mathrm{~kg}$ and a standard deviation of $5.7 \mathrm{~kg}$. Primiparous cows tended to have smaller calves $(38.2 \mathrm{~kg})$ than multiparous cows $(41.7 \mathrm{~kg}$ ) (see Table 2). Once ratio is considered in the model, smaller birth weights tend to have lower risk of mortality. Birth weights above the average of 40.3 have an exponentially increasing risk of mortality. Probabilities of perinatal mortality for birth weights of 29, 35, 40, 46 , and $52 \mathrm{~kg}$ were $2.1,2.5,3.4,5.1$, and $9.6 \%$, respectively, when other factors were set at their average value.

Gestation length. Figure 3 demonstrates the impact of gestation length on risk of mortality. The mean gesta-

Table 6. Odds ratio (OR) estimates and interpretations for best perinatal mortality (PM) model (model 2, Table 4).

\begin{tabular}{lllll}
\hline Effect & Comparison & OR & $95 \%$ CI & Interpretation ${ }^{1}$ \\
\hline Year & Linear trend & 1.02 & $(1.006,1.04)$ & $2.1 \%$ increase in odds for PM per year \\
Season & Winter vs. summer & 1.36 & $(1.07,1.74)$ & $36 \%$ higher odds for PM in winter than summer \\
Dystocia & Assist vs. unassist & 2.71 & $(2.07,3.54)$ & 2.7 times higher odds for PM when assisted than unassisted \\
Parity & 1 vs 2+ & 2.43 & $(1.68,3.51)$ & 2.4 times higher odds for PM in first than later parities \\
\hline
\end{tabular}

${ }^{1}$ Change in odds for PM. 
tion length is $278.7 \mathrm{~d}$ with a standard deviation of 5.6 d. First-parity cows had a shorter gestation length than later-parity cows at 277.9 and $279.2 \mathrm{~d}$, respectively (Table 2). The graph shows gestation length ranging over approximately two standard deviations from 268 to 290 d. Similar to the findings of Meyer et al. (2000), short gestation lengths are the most problematic. Gestation lengths of $268,273,279,284$, and $290 \mathrm{~d}$ yield probabilities of mortality of $5.5,3.9,3.1,3.1$, and $3.6 \%$, respectively. The graph indicates the intermediate value that minimizes the risk of PM is $282 \mathrm{~d}$, which is longer than the accepted breed average of $280 \mathrm{~d}$.

\section{Dystocia Model Analysis}

Logistic regression model. Similar to the procedure done for PM, the most parsimonious model for dystocia was found to include year, season, sex, perinatal mortality, parity, birth weight (only a linear effect), and pelvic area (PA). We chose to include PM in the model for dystocia to adjust for the average difference in incidence of PM associated with each level of dystocia. If a dairy producer wants to know that a cow is at high risk for a difficult calving, he cannot know in advance if the calf will die. In this case, PM is not helpful in the model. However, future genetic evaluations of sires for calving ease could conceivably incorporate PM in the model to enhance the evaluation of sires for calving ease. Perinatal mortality will be known at the same time as calving ease and will be easy to incorporate in revised sire evaluation procedures. Therefore, PM was retained in one model and deleted from another model to evaluate the effect of including or ignoring PM. Table 7 compares a few of the models for dystocia. Model 1 is the best model with the highest MRR2 value of $26.6 \%$ and the lowest AIC value. Similar to the models for PM, model 1 in-
Table 8. Parameter estimates for best dystocia model (model 1, Table 7).

\begin{tabular}{lc}
\hline Parameter & Estimate \\
\hline Intercept & 91.7248 \\
Year & -0.0480 \\
Season (winter) & 0.1435 \\
Sex (male) & 0.2263 \\
PM (dead) & 0.8982 \\
Parity (first) & 1.5523 \\
Birth weight $(\mathrm{kg})$ & 0.1188 \\
Pelvic area $\left(\mathrm{dm}^{2}\right)$ & -0.00121 \\
\hline
\end{tabular}

cludes all significant effects. Model 2 ignores the effect of PM, assuming that PM is unknown prior to birth according to the discussion earlier in this paragraph. Model 2 is a slightly less efficient predictor of dystocia than model 1; it has $1.1 \%$ less predictive value and the AIC is larger. Model 3 ignores the effect of birth weight. Without birth weight in the model, we lose approximately $1 / 5$ of our predictive ability, dropping the MRR2 down to $20.0 \%$. This model has fewer significant factors than the model for PM making this model slightly simpler. The best logistic regression model for dystocia is given as

$$
\begin{gathered}
\log \left(\Pi_{\mathrm{DYS}} /\left(1-\Pi_{\mathrm{DYS}}\right)\right)=\beta_{0}+\beta_{1} \text { Year }+\beta_{2} \text { Season }+\beta_{3} \text { Sex } \\
+\beta_{4} \mathrm{PM}+\beta_{5} \text { Parity }+\beta_{6} \mathrm{BW}+\beta_{7} \mathrm{PA}
\end{gathered}
$$

where $\Pi_{\mathrm{DYS}}$ is the probability of dystocia and BW is birth weight. Table 8 gives significant parameters along with their estimates. The first thing that one may notice is the significant differences in this model compared with the model for PM. Factors contributing to PM may not be contributing to an increase in incidences of dystocia. Here, in contrast with PM, sex of calf is a significant factor, whereas ratio is not. For analyzing dystocia, the effect of pelvic area accounts for the size of the cow

Table 7. A comparison of three different models for dystocia. The $P$-values demonstrate the level of significance for each effect. Model 1 is the best model because it has the largest MRR2 value and the smallest AIC.

\begin{tabular}{lccr}
\hline Effects of Dystocia & Model $1^{1}$ & Model $2^{2}$ & Model $3^{3}$ \\
\hline Year & $<0.0001^{4}$ & $<0.0001$ & $<0.0001$ \\
Season & 0.0805 & 0.0505 & 0.0470 \\
Sex & 0.0072 & 0.0064 & $<0.0001$ \\
Perinatal mortality & $<0.0001$ & - & $<0.0001$ \\
Parity & $<0.0001$ & $<0.0001$ & $<0.0001$ \\
Birth weight & $<0.0001$ & $<0.0001$ & - \\
Pelvic area & $<0.0001$ & $<0.0001$ & $<0.0001$ \\
AIC & 3727 & 0.2546 & 3937 \\
MRR2 & 0.2655 & 0.2000 \\
\hline
\end{tabular}

\footnotetext{
${ }^{1}$ Model 1 includes all effects. Note that Model 1 is the best model with the lowest AIC and the highest MRR2.

${ }^{2}$ Model 2 drops the PM effect.

${ }^{3}$ Model 3 also drops the birth weight effect.

${ }^{4} P$-value to test significance of the effect.
} 
Table 9. Odds ratio (OR) estimates and interpretations for best dystocia model (model 1, Table 7).

\begin{tabular}{|c|c|c|c|c|}
\hline Effect & Comparison & OR & $95 \% \mathrm{CI}$ & Interpretation $^{4}$ \\
\hline Year & Linear trend & 0.95 & $(0.94,0.96)$ & $4.7 \%$ decrease in odds for dystocia per year \\
\hline Season & Winter vs. summer & 1.15 & $(0.98,1.36)$ & $15 \%$ higher odds for dystocia in winter than summer \\
\hline Sex & Male vs. female & 1.25 & $(1.06,1.48)$ & $25 \%$ higher odds for dystocia in males than females \\
\hline Parity & 1 vs $2+$ & 4.72 & $(3.77,5.91)$ & 4.7 times higher odds for dystocia in first than later parities \\
\hline $\mathrm{BW}^{2}$ & Linear trend & 1.13 & $(1.11,1.15)$ & $13 \%$ increase in odds for dystocia per $\mathrm{kg}$ increase in BW \\
\hline $\mathrm{PA}^{3}$ & Linear trend & 0.89 & $(0.86,0.92)$ & $11 \%$ decrease in odds for dystocia per $\mathrm{dm}^{2}$ increase in PA \\
\hline
\end{tabular}

${ }^{1} \mathrm{PM}=$ perinatal mortality.

${ }^{2} \mathrm{BW}=$ calf's birth weight.

${ }^{3} \mathrm{PA}=$ pelvic area.

${ }^{4}$ Change in odds for dystocia.

better than ratio does. Also note that the quadratic term for birth weight is not necessary to predict dystocia. This is due to the fact that smaller than average birth weights do not need assistance as often as larger than average birth weights. The linear trend of birth weight is sufficient to model the increase in dystocia.

Odds ratios. Table 9 has estimates of the OR for the factors in the dystocia model. The estimate of the OR

Table 10. Several combinations of model predictions for PM. Three combinations are listed at each percentile.

\begin{tabular}{|c|c|c|c|c|c|c|c|c|}
\hline Percentile & Year $^{1}$ & Season $^{2}$ & Dystocia $^{3}$ & Parity ${ }^{4}$ & Ratio $^{5}$ & $\mathrm{BWT}^{6}$ & $\mathrm{GL}^{7}$ & PM (\%) \\
\hline \multirow[t]{3}{*}{ Min } & 1970 & 0 & 0 & 0 & 6.9 & 29 & 279 & 0.8 \\
\hline & 1970 & 0 & 0 & 0 & 6.9 & 29 & 290 & 0.9 \\
\hline & 1970 & 0 & 0 & 0 & 6.9 & 40 & 279 & 1.1 \\
\hline \multirow[t]{3}{*}{$10 \%$} & 1970 & 1 & 0 & 0 & 4.5 & 29 & 279 & 3.0 \\
\hline & 1970 & 1 & 1 & 0 & 6.9 & 29 & 279 & 3.0 \\
\hline & 1988 & 1 & 0 & 0 & 9.3 & 29 & 290 & 3.0 \\
\hline \multirow[t]{3}{*}{$20 \%$} & 1995 & 1 & 0 & 0 & 6.9 & 40 & 268 & 4.5 \\
\hline & 1970 & 1 & 0 & 1 & 9.3 & 29 & 279 & 4.6 \\
\hline & 1995 & 0 & 0 & 0 & 6.9 & 52 & 279 & 4.6 \\
\hline \multirow[t]{3}{*}{$30 \%$} & 1970 & 1 & 0 & 0 & 9.3 & 52 & 279 & 6.3 \\
\hline & 1970 & 1 & 0 & 1 & 9.3 & 40 & 290 & 6.3 \\
\hline & 1995 & 1 & 0 & 0 & 4.5 & 40 & 279 & 6.3 \\
\hline \multirow[t]{3}{*}{$40 \%$} & 1988 & 0 & 0 & 1 & 4.5 & 29 & 290 & 8.2 \\
\hline & 1988 & 0 & 1 & 1 & 6.9 & 29 & 290 & 8.2 \\
\hline & 1988 & 1 & 0 & 1 & 9.3 & 40 & 279 & 8.2 \\
\hline \multirow[t]{3}{*}{$50 \%$} & 1970 & 1 & 0 & 0 & 4.5 & 52 & 290 & 10.4 \\
\hline & 1970 & 1 & 1 & 0 & 6.9 & 52 & 290 & 10.4 \\
\hline & 1995 & 1 & 0 & 1 & 6.9 & 40 & 268 & 10.4 \\
\hline \multirow[t]{3}{*}{$60 \%$} & 1970 & 0 & 1 & 1 & 4.5 & 29 & 279 & 13.2 \\
\hline & 1988 & 0 & 1 & 1 & 9.3 & 29 & 290 & 13.2 \\
\hline & 1970 & 0 & 1 & 0 & 4.5 & 40 & 268 & 13.2 \\
\hline \multirow[t]{3}{*}{$70 \%$} & 1995 & 0 & 0 & 1 & 9.3 & 52 & 279 & 16.8 \\
\hline & 1970 & 1 & 0 & 0 & 4.5 & 52 & 268 & 16.8 \\
\hline & 1970 & 1 & 1 & 0 & 6.9 & 52 & 268 & 16.8 \\
\hline \multirow[t]{3}{*}{$80 \%$} & 1988 & 1 & 1 & 0 & 9.3 & 52 & 290 & 22.3 \\
\hline & 1970 & 1 & 1 & 1 & 4.5 & 40 & 290 & 22.4 \\
\hline & 1970 & 0 & 1 & 1 & 4.5 & 29 & 268 & 22.4 \\
\hline \multirow[t]{3}{*}{$90 \%$} & 1988 & 1 & 0 & 1 & 9.3 & 52 & 268 & 31.1 \\
\hline & 1988 & 1 & 1 & 0 & 4.5 & 52 & 290 & 31.2 \\
\hline & 1988 & 1 & 1 & 1 & 9.3 & 40 & 268 & 31.6 \\
\hline \multirow[t]{3}{*}{ Max } & 1995 & 0 & 1 & 1 & 4.5 & 52 & 268 & 62.1 \\
\hline & 1988 & 1 & 1 & 1 & 4.5 & 52 & 268 & 65.9 \\
\hline & 1995 & 1 & 1 & 1 & 4.5 & 52 & 268 & 69.1 \\
\hline
\end{tabular}

${ }^{1}$ Years considered are 1970, 1988, and 1995.

${ }^{2}$ Season is $0=$ summer or $1=$ winter.

${ }^{3}$ Dystocia of $0=$ unassisted or $1=$ assisted.

${ }^{4}$ Parity is $1=$ first or $0=$ later.

${ }^{5}$ Ratio (\%) is calf birth weight divided by cow weight $2 \mathrm{~d}$ after parturition.

${ }^{6} \mathrm{BWT}$ is the calf's birth weight $(\mathrm{kg})$.

${ }^{7} \mathrm{GL}$ is gestation length (d). 
for year tells us that there is a $4.7 \%$ decrease in dystocia per year. For example, if the incidence of dystocia is $23.7 \%$ in a given year, then it will decrease to $22.52 \%$ $(0.237 \times 0.95)$ the next year. The effect of season on dystocia is about half that for PM. Calves born in the winter are $15 \%$ more likely to need assistance than calves born in the summer. Male calves tend to need assistance $25 \%$ more often than female calves. The effect of PM means that if a calf died in the first $48 \mathrm{~h}$, then it had a 2.5 times greater chance that it needed assistance given that all other factors are held constant. The most noteworthy OR estimate is for parity. A first-parity cow has 4.7 times higher risk of dystocia than later-parity cows. A $1-\mathrm{kg}$ increase in birth weight corresponds to a $13 \%$ increase in dystocia. Finally, a $1-\mathrm{dm}^{2}$ increase in pelvic area means that there is an $11 \%$ decrease in incidence of dystocia.

If PM is dropped from the dystocia model (See model 2 in Table 7), there is only a slight change in the OR estimates, which is as we would expect from the small drop in MRR2 value of this model. The OR estimates for the model without PM are 0.95 for year, 1.17 for season, 1.26 for sex, 5.02 for parity, 1.13 for birth weight, and 0.88 for pelvic area. Compare these with the OR estimates in Table 9.

\section{CONCLUSIONS}

Our results clearly demonstrate that dystocia and PM are not the same traits and do not yield the same predictive model. Dystocia and PM, however, are correlated traits, so some of the effects are in both models. The phenotypic correlation between PM and dystocia is 0.18 . On the other hand, $49 \%$ of the deaths were associated with unassisted births. Berger et al. (1992) observed that most mortality occurred with unassisted births. Birth weight is a valuable predictor of both PM and dystocia. In the future, dairy producers should measure birth weights of calves. Dairy producers often handle the calf within the first $48 \mathrm{~h}$ of birth, so measuring the weight by scale, or even by heart girth tape or hip height would mean a small amount of additional handling. Also, there is evidence that we should measure the weights of cows shortly after parturition, because ratio was a useful predictor of PM. There is some evidence that pelvic measurements should be measured, because of their value in predicting dystocia. Literature suggests that internal measurements would be better, but our work here demonstrates value in the easy-to-measure external values. Another interesting result is that PM seems to be increasing over time, while dystocia appears to be decreasing. Due to their positive correlation, one would expect $\mathrm{PM}$ and dystocia to have trends in the same direction.

\section{ACKNOWLEDGMENTS}

The availability of this data is credited to A. E. Freeman and the Ankeny farm support staff for their 30 years of hard work. We also would like to thank Ken Koehler and Heike Hofmann for their statistical guidance. We appreciate the computer support of Mary Healey and her ability to organize the necessary data for analysis.

\section{REFERENCES}

Akaike, H. 1969. Fitting autoregressive models for prediction. Ann. Inst. Stat. Math. 21:243-247.

Agresti, A. 2002. Pages 216-217 in Categorical Data Analysis. John Wiley \& Sons, Inc., Hoboken, NJ.

Berger, P. J., A. C. Cubas, K. J. Koehler, and M. H. Healey. 1992. Factors affecting dystocia and early calf mortality in Angus cows and heifers. J. Anim. Sci. 70:1775-1786.

Dekkers, J. C. M. 1994. Optimal breeding strategies for calving ease. J. Dairy Sci. 77:3441-3453.

Dematawewa, C. M. B., and P. J. Berger. 1997. Effect of dystocia on yield, fertility, and cow losses and an economic evaluation of dystocia scores for Holsteins. J. Dairy Sci. 80:754-761.

Hosmer, D. W., and S. Lemeshow. 2000. Applied Logistic Regression. 2nd Ed. John Wiley \& Sons, Inc., New York, NY.

Johanson, J. M., P. J. Berger, B. W. Kirkpatrick, and M. R. Dentine. 2001. Twinning rates of North American Holstein sires. J. Dairy Sci. 84:2081-2088.

Kleinbaum, D. G. 1994. Logistic Regression: A self-learning text. Springer-Verlag New York, Inc., New York, NY.

McDermott, J. J., O. B. Allen, S. W. Martin, and D. M. Alves. 1992. Patterns of stillbirth and dystocia in Ontario cow-calf herds. Can. J. Vet. Res. 56:47-55.

Meijering, A. 1984. Dystocia and stillbirth in cattle-a review of causes, relations and implications. Livest. Prod. Sci. 11:143-177.

Meyer, C. L., P. J. Berger, and K. J. Koehler. 2000. Interactions among factors affecting stillbirths in Holstein cattle in the United States. J. Dairy Sci. 83:2657-2663.

Meyer, C. L., P. J. Berger, K. J. Koehler, J. R. Thompson, and C. G. Sattler. 2001a. Phenotypic trends in incidence of still births for Holsteins in the United States. J. Dairy Sci. 84:515-523.

Meyer, C. L., P. J. Berger, J. R. Thompson, and C. G. Sattler. 2001b. Genetic evaluation of Holstein sires and maternal grandsires in the United States for perinatal survival. J. Dairy Sci. 84:1246-1254.

Nagelkerke, N. J. D. 1991. A note on a general definition of the coefficient of determination. Biometrika 78:691-692.

SAS. 1999. SAS/STAT User's Guide. Version 8 Edition. SAS Inst. Inc., Cary, NC.

Sieber, M., A. E. Freeman, and D. H. Kelley. 1989. Effects of body measurements and weight on calf size and calving difficulty of Holsteins. J. Dairy Sci. 72:2402-2410.

\section{APPENDIX}

Calculating PM (\%) estimates. We considered all 648 permutations of the following: $2 \mathrm{yr}(1970,1988$, and 1995), 2 seasons ( $0=$ summer and $1=$ winter), 2 dystocia statuses $(0=$ unassisted and $1=$ assisted $), 2$ parity groups ( $1=$ primiparous and $0=$ multiparous), 3 ratios $(4.5,6.9$, and $9.3 \%), 3$ birth weights $(29,40$, and $52 \mathrm{~kg})$, and 3 gestation lengths $(268,279$, and 290). The three values for ratio, birth weight, and gestation length represent the mean minus two standard deviations, the mean, and the mean plus two standard deviations. Table 10 lists 
three permutations and their respective estimate of PM at each tenth of a percentile. We can see that the model can give us a wide range of estimates from $0.8 \%$ to $69.1 \%$. For example at the sixtieth percentile, we can use equation [1] and the parameter estimates in Table 7 to calculate the estimate of PM.

$$
\begin{gathered}
\log \left(\Pi_{\mathrm{PM}} /\left(1-\Pi_{\mathrm{PM}}\right)\right)=206.7+0.021 \times 1970 \\
+0.31 \times 0+0.99 \times 1+0.89 \times 1 \\
+-1.93 \times 4.5+0.13 \times 4.5^{2}+-0.15 \times 29+0.0025 \\
\times 29^{2}+-1.71 \times 279+0.003 \times 279^{2}=-1.89
\end{gathered}
$$

Then solve for $\Pi_{\mathrm{PM}}$ to get $\Pi_{\mathrm{PM}}=0.132$. Finally, multiply 0.132 by $100 \%$ to get the estimate of $13.2 \%$. Following this example, one can calculate the estimate of PM for any situation one might encounter.
As is the case with most predictive models, concern arises when one uses the model to predict a situation where any one variable is an outlier. With this particular model, special caution is needed when both ratio and birth weight are outliers. Consider, for example, the situation where $\mathrm{PM}$ is maximized in Table 10. A ratio of $4.5 \%$, which is 2 standard deviations below average, and a birth weight of $52 \mathrm{~kg}$, which is 2 standard deviations above average, implies the cow's weight is $1156 \mathrm{~kg}$ (2542 $\mathrm{lb}$ ), which is very unlikely.

Also, one should note that some factors might compensate for other factors. For the first example in the $60 \%$ of Table 10, a calf with low birth weight $(29 \mathrm{~kg})$ and average GL ( $279 \mathrm{~d}$ ) would normally have a low risk for PM, but this example also has a need for assistance of a small ratio scenario in the first parity, which substantially raises the risk of PM. 